$\underline{\text { Avicenna Journal of Nursing and Midwifery Care - ISSN 2676-5748 }}$

\title{
Design and Psychometric Properties of the Persian Version of Hysterectomy Women's Educational Needs Questionnaire (HWENQ)
}

\section{Fereshteh Shabani-Asrami ${ }^{1}$, Zeinab hamzehgardeshi*2, Mahmonir Danesh ${ }^{3}$, Mahmood Moosazadeh $^{4}$}

1. MSc in Counseling in Midwifery, Student Research Committee, Faculty of Nursing and Midwifery, Mazandaran University of Medical Sciences, Sari, Iran

2. Associate Professor, Department of Reproductive Health and Midwifery, Nasibe Faculty of Nursing and Midwifery, Mazandaran University of Medical Sciences, Sari, Iran

3. Instructor, Department of Midwifery, Mazandaran University of Medical Sciences, Faculty of Nursing and Midwifery, Sari, Iran

4. Assistant Professor, Health Sciences Research Center, Addiction Institute, Mazandaran University of Medical Sciences, Sari, Iran

\section{Article Info}

Received: 2020/01/23;

Accepted: 2020/04/29;

Published Online: 2020/08/22

10.30699/ajnmc.28.3.205

Original Article

Use your device to scan and read the article online

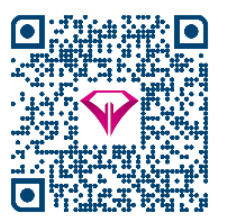

\section{ABSTRACT}

Introduction: Despite that hysterectomy is the second gynecological surgery and providing the necessary information about this surgery will help women's positive perceptions of health care experiences, there is no comprehensive tool for examining the educational needs of women with hysterectomy. Therefore, the present study was conducted with the aim of designing and psychometric evaluation of the women's educational needs questionnaire after hysterectomy.

Methods: The initial version of the questionnaire of this methodological study was compiled by deductive and comprehensive overview of related resources considering the point of view of a group of specialists and women with hysterectomy history. The face and content validity of both qualitative and quantitative data and reliability of the questionnaire in the dimension of internal consistency and then the repeatability were examined.

Results: Developing the questionnaire for women's educational needs after hysterectomy and psychometrics led to the formation of a questionnaire for women's educational needs after hysterectomy with 44 questions and in 5 dimensions: physical, mental, sexual, care and other needs. The CVR index for all items in the questionnaire except for one item was above the Lawshe table criterion, which indicated the importance and necessity of each item. The CVI for each item was above 0.79 and was therefore considered appropriate. Also, the reliability of the instrument in terms of internal coherence by examining the Cronbach's alpha coefficient for the whole instrument was 0.90. Measurement of the repeatability index at two-week intervals showed that the instrument was stable $(\mathrm{ICC}=0.97, P<0.001)$.

Conclusion: The Hysterectomy Women's Educational Needs Questionnaire is valid and reliable. It can be used by public health researchers and health system policy makers to provide patient-centered health services based on the needs and priorities of patients.

Keywords: Psychometric, Educational Needs Assessment, Hysterectomy, Women

Copyright $($ ) 2020, This is an original open-access article distributed under the terms of the Creative Commons Attribution-noncommercial 4.0 International License which permits How to Cite This Article: copy and redistribution of the material just in noncommercial usages with proper citation.

Shabani-Asrami F, Hamzehgardeshi Z, Danesh M, Moosazadeh M. Design and Psychometric Properties of the Persian Version of Hysterectomy Women's Educational Needs Questionnaire (HWENQ). Avicenna J Nurs Midwifery care. 2020; 28(3): 205-215 


\title{
طراحى و روانسنجى نسخة فارسى يرسشنامهُ نيازهاى آموزشى زنان بعد از هيستر كتومى

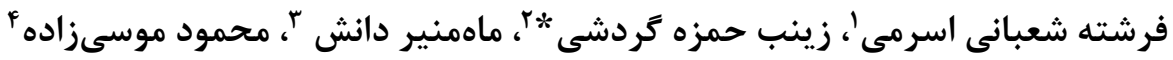

\author{
' . كارشناسىارشد مشاوره در مامايى، مركزتحقيقات دانشجويى، دانشخاه علوميزشكى مازندران، سارى، ايران \\ Y. . دانشيار، مركزتحقيقات سلامت جنسى و بارورى، دانشكاه علوميزشكى مازندران، سارى، ايران \\ ؟ّ. كارشناسىارشد مامايى، دانشكده يرستارى و مامايى، دانشكاه علوميزشكى مازندران، سارى، ايران \\ †. استاديار، مركزتحقيقات علوم بهداشتى، يروهشكده اعتياد، دانشعاه علوميزشكى مازندران، سارى، ايران
}

\begin{tabular}{|c|c|}
\hline جكيده & اطلاعات مقاله \\
\hline 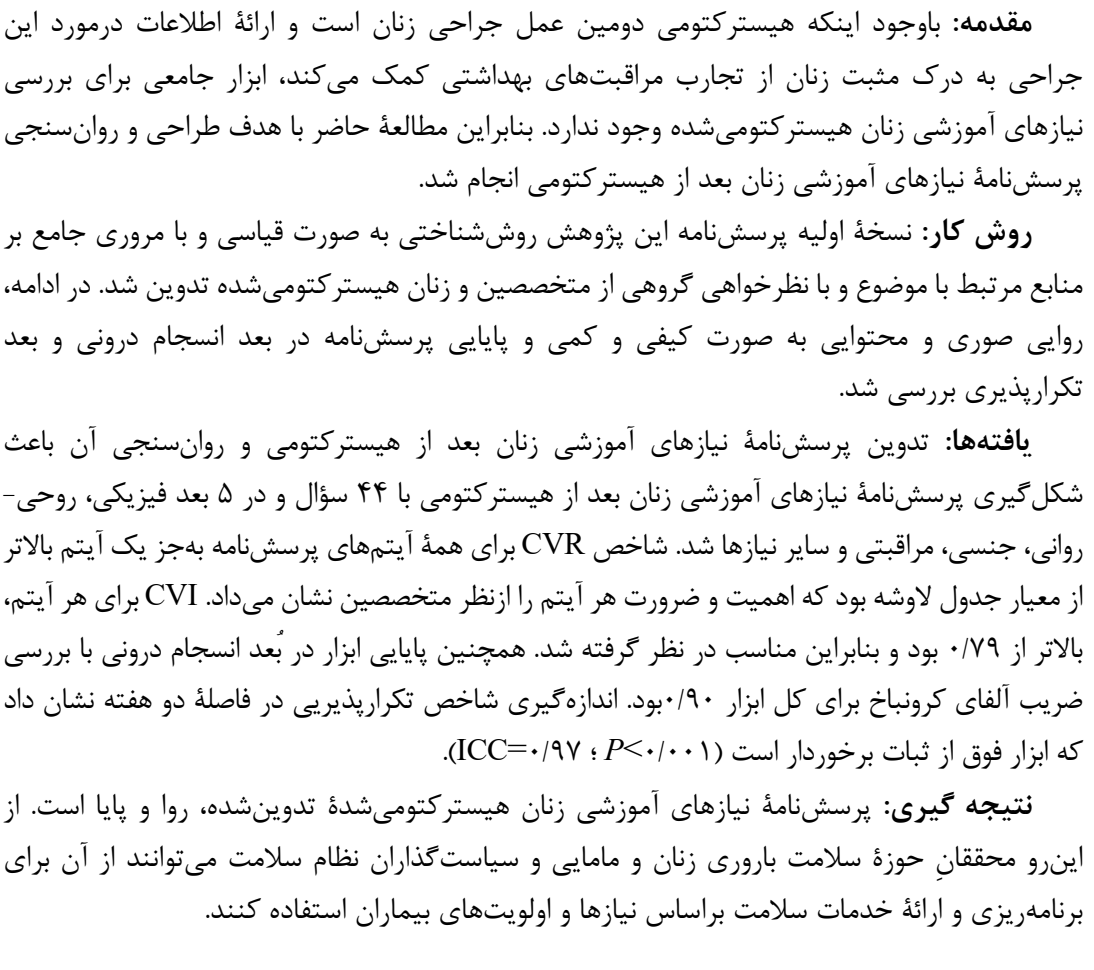 & 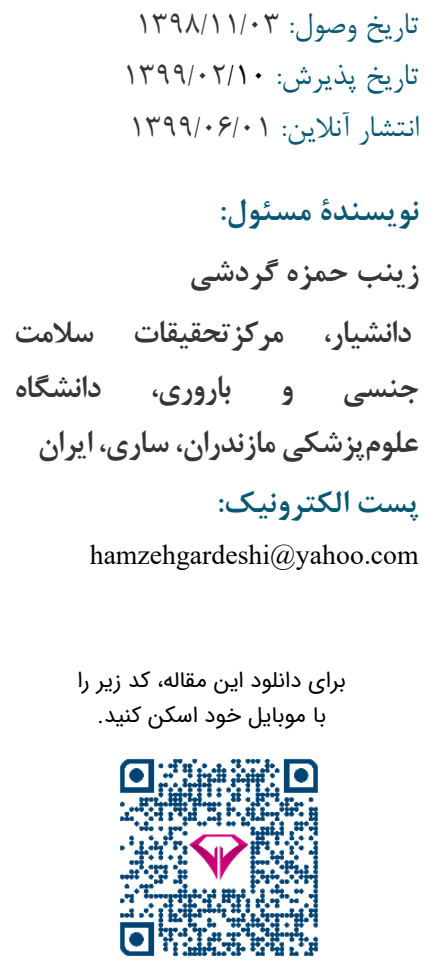 \\
\hline كليدوازٔها: روانسنجى، ارزيابى نيازهاى آموزشى، هيستركتومى، زنان & \\
\hline
\end{tabular}

باقى مانده است [ع، ،ه]. براساس ززارش سازمان جهانى

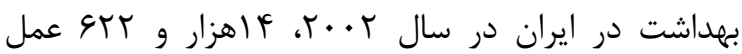

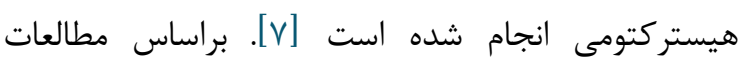

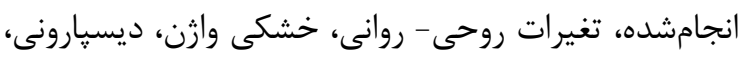

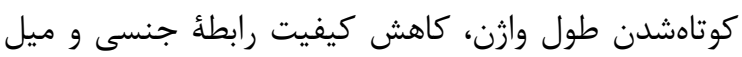

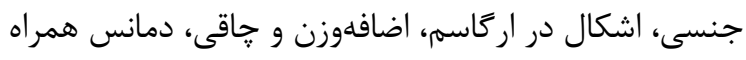

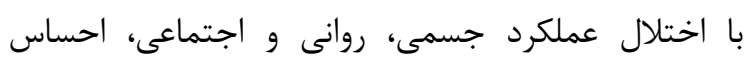

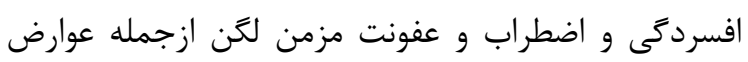

هيستر كتومى عملى است كه در آن رحم، سرويكس و

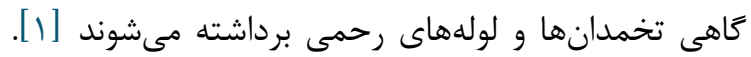
اين عمل يس از سزارين دومين عمل جراحى رايج در زنان

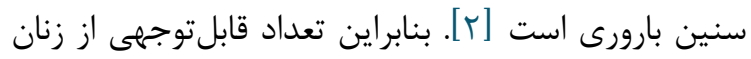

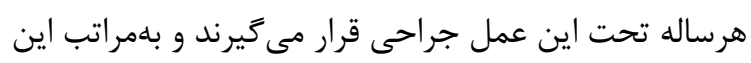
جراحى بيشتر از بسيارى از اعمال جراحى رايج ديگر انجام

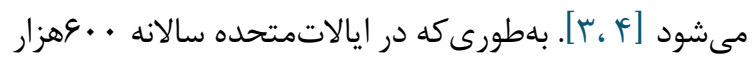
زن تحت هيستر كتومى قرار مى گيرند و اين عدد نسبتأ ثابت 
قرار خواهد كرفت [1/1]؛؛ از اينرو امروزه جهت تعيين كفايت

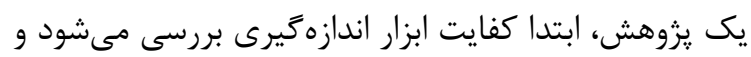

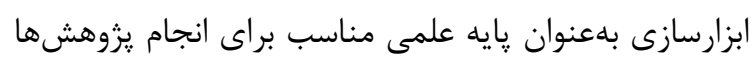

$$
\text { منظور مى كردد. }
$$

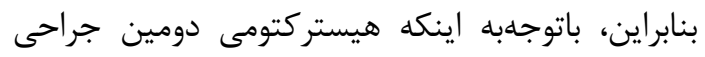

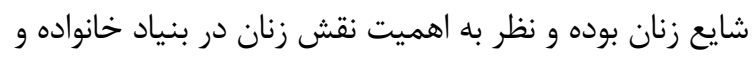

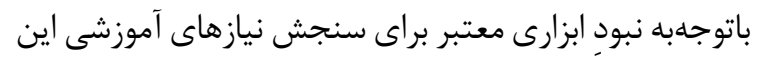

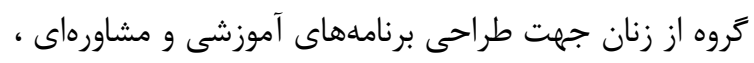

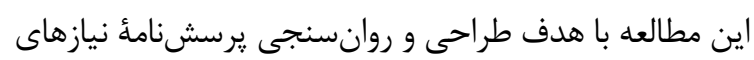
آموزشى زنان هيستر كتومىشده انجام شد.

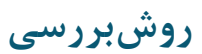

Methodological (يزوهش حاضر يك مطالعه روش شناختى (Research

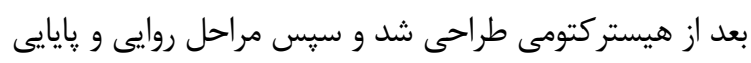
راطى كرد.

نسخة اوليه يرسشنامُٔ حاضر به صورت قياسى و با

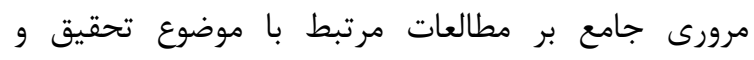

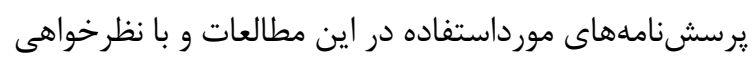

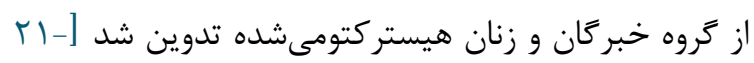

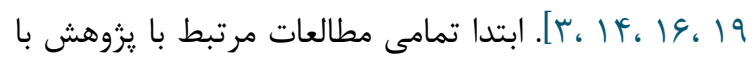

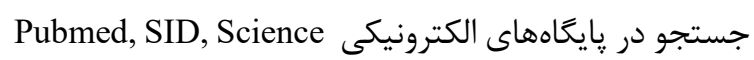
Direct, GoogleScholar, Scopus, Chochraine Library, باستفادهاز كلمات كليدى هيستر كتومى، زنان Magiran

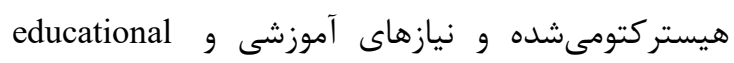
needs, hysterectomy, hysterectomy women

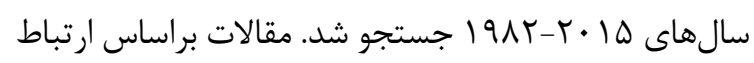

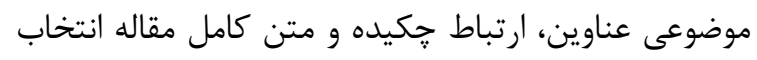

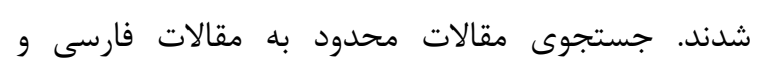
انغليسى بود و مقالات شامل مقالات كمّى و كيفى بودند. مقدات

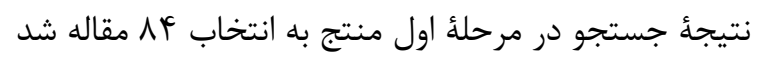

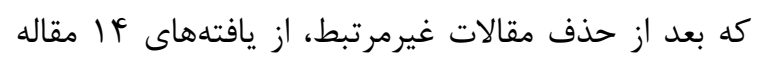
براى تشكيل استخر سؤالات (Pool of items) استفاده شد.

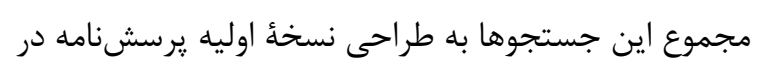

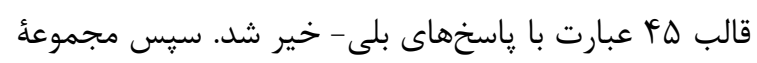

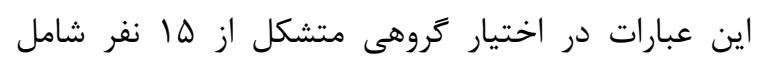

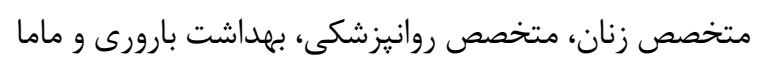

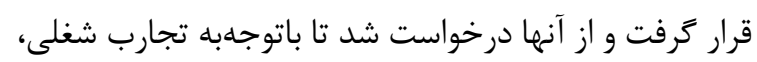

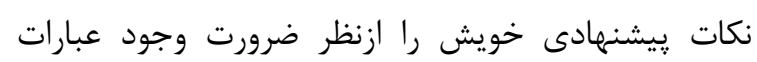

ناشى از هيستركتومى هستند [ [1 1 ، ،ه]. بنابراين، بهترين

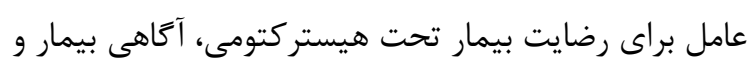

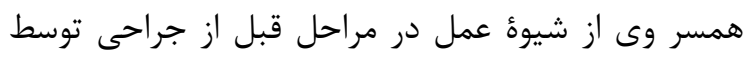

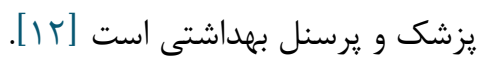

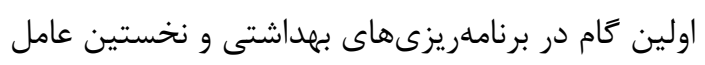

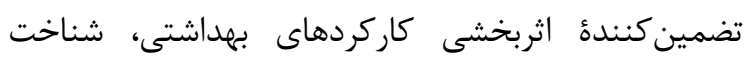

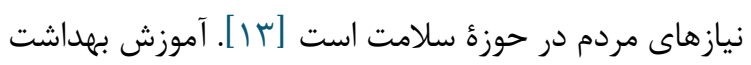

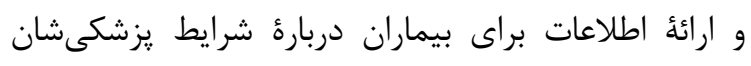

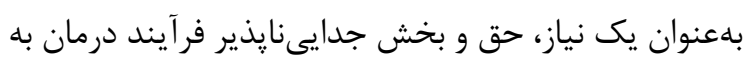

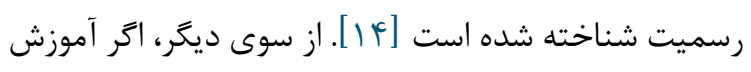

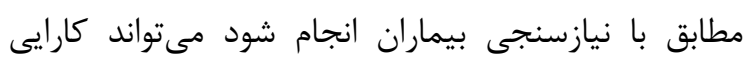

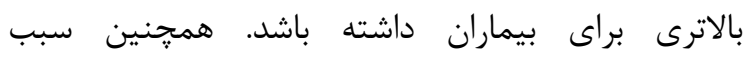

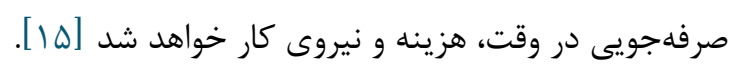

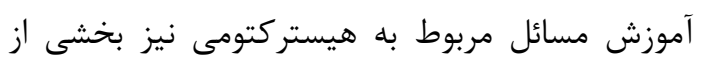

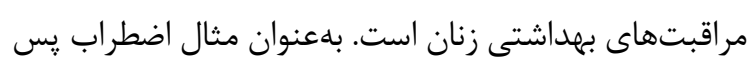

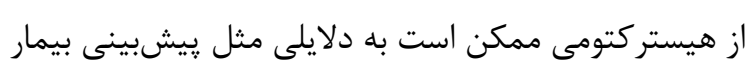

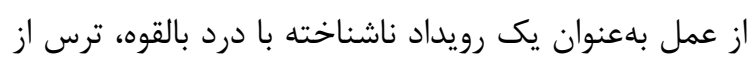

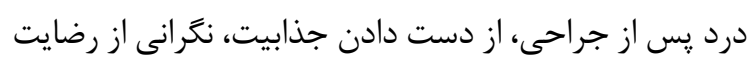

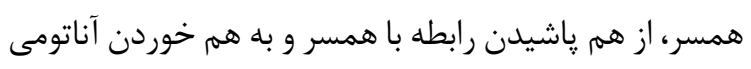
كلى بدن باشد. مطالعه Graff در سال هـ 199 1 باستفادهاز ابزار

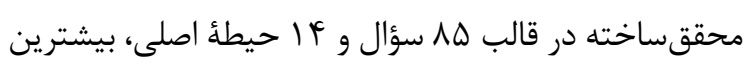

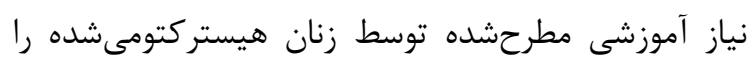

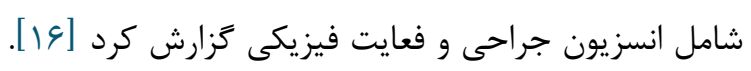

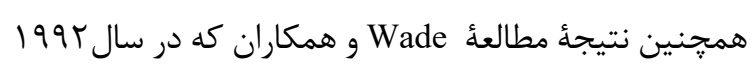
باستفادهاز يرسشنامئ محققساخته با سؤالات باز انجام شد،

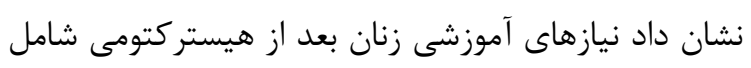

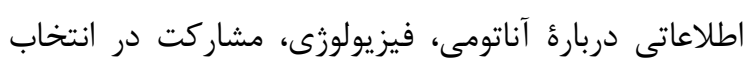

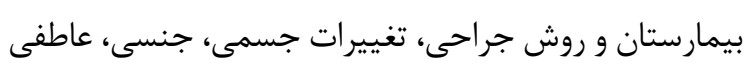

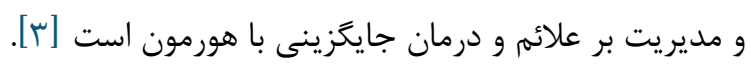

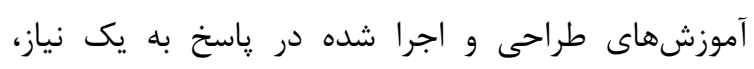

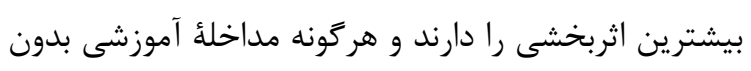
توجه به نيازهاى آموزشى، درواقع نوعى اتلاف منابع ارزشمند دارند

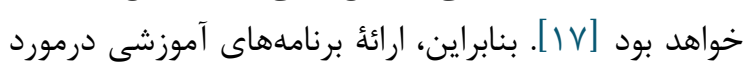

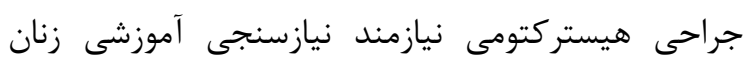

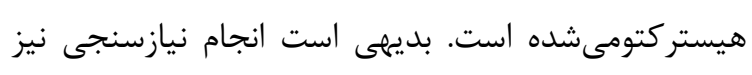

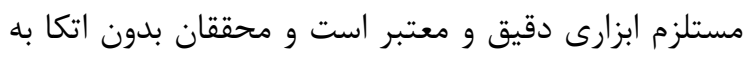

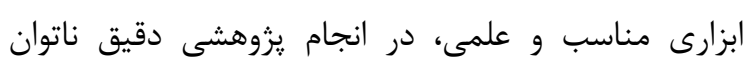

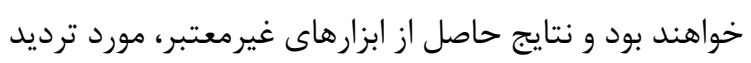




\section{روايى صورى كيفى}

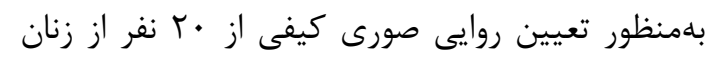

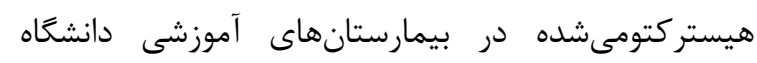

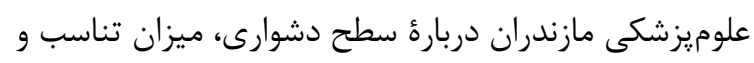

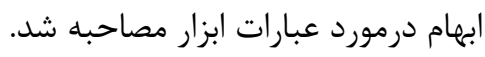

\section{روايى صورى كمى}

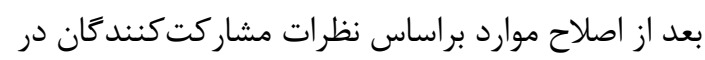

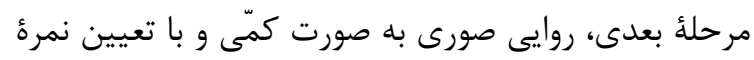

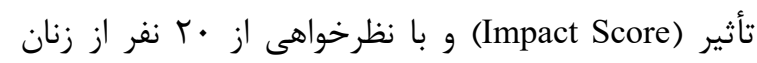

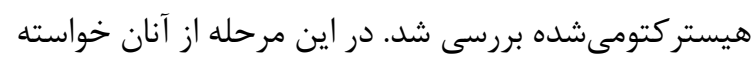

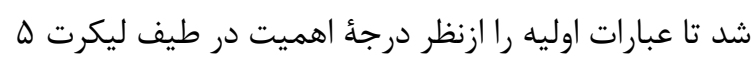

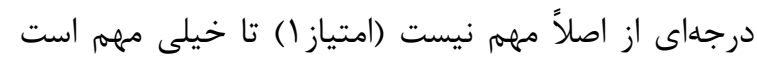

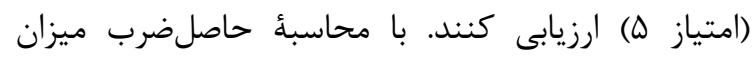

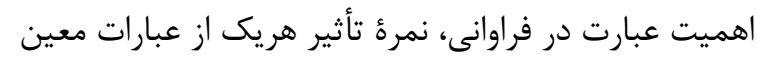

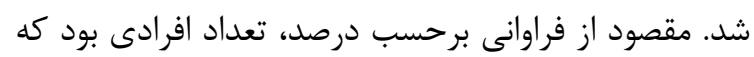

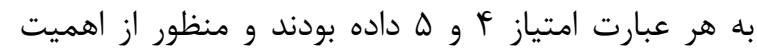
ميانكَين نمرءٔ اهميت براساس طيف ليكرت ذكر شده بود. در

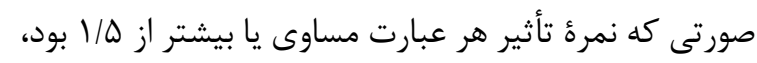

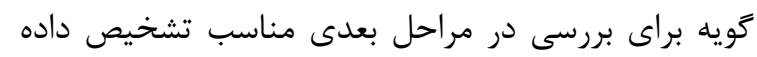
شده و حفظ مى گرديد [1/1].

\section{روايى محتوا}

براى تعيين روايى محتواى ابزار از دو روش كمّى و كيفى

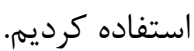

روايى محتواى كيفى باستفادهازنظرات بانفي انفر از افراد

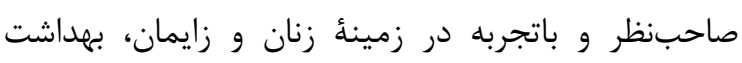

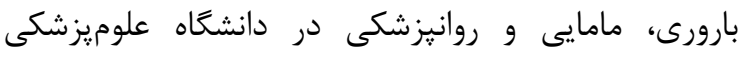

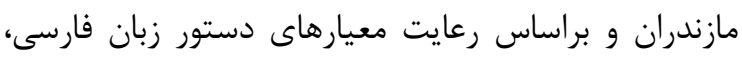

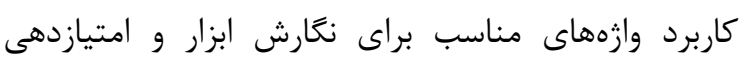

$$
\text { متناسب ارزيابى شد. }
$$

در اين مرحله با اندازمخيرى نسبت روايى محتوا (Content Validity Ratio) I و و طى نظرخواهى از (Content Validity Index) متخصص روايى محتوا به روش كمّى ارزيابى شد. ابتدا از

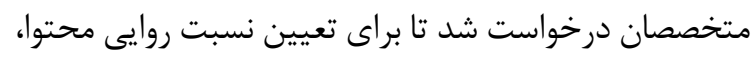
هر عبارت را براساس طيف ب ليكرتى (ضرورى است، مفيد است ولى ضرورى نيست و ضرورتى ندارد) بررسى كنند. بعد إنى
بيشتر درباره نيازهاى آموزشى زنان هيستر كتومىشده ذكر

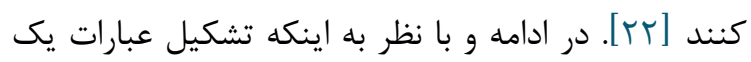

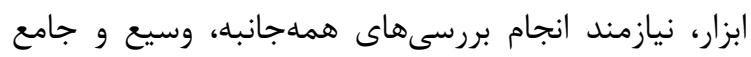

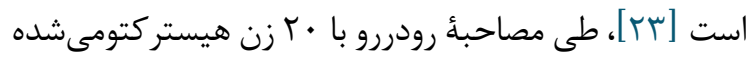
كه به صورت در دسترس انتخاب شده بودند نسخئ اوليه

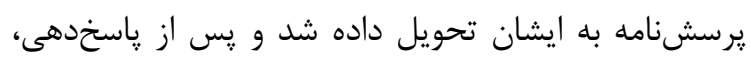

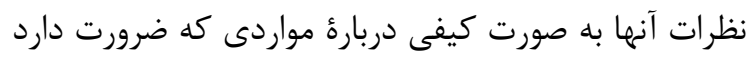

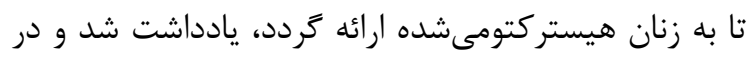

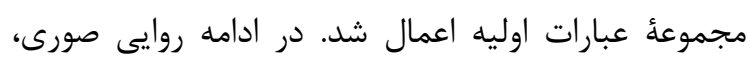

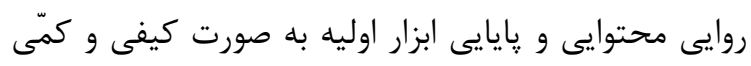

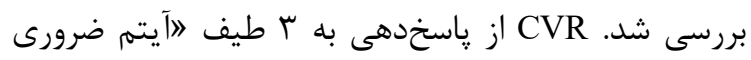

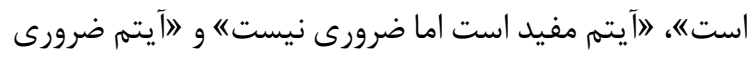

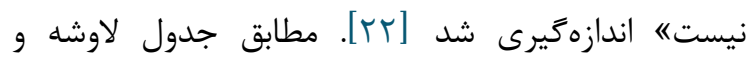
براساس فرمول شماره l، ارزش CVR

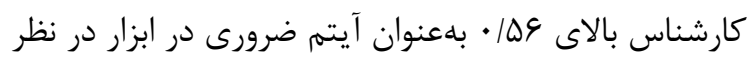

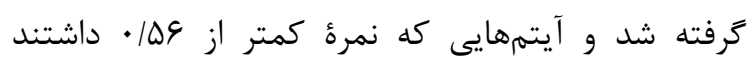

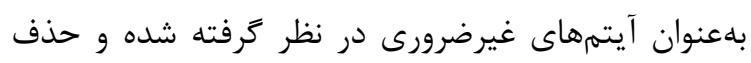

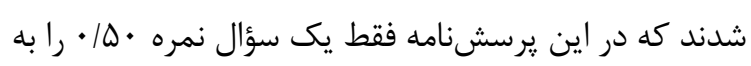
دست آورد و حذف ترديد.

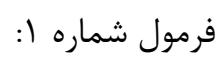

$\mathrm{CVR}=\frac{n E-\frac{N}{2}}{\frac{N}{2}}$

سيس CVI براى بيان نظرات دربارة واضحبودن،

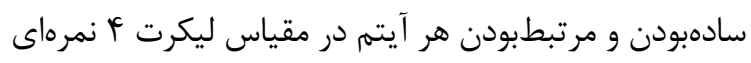

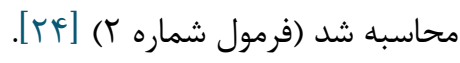

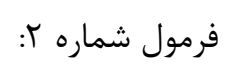

CVI $=\frac{\text { number of raters giving a rating of }{ }^{\prime} 3{ }^{\prime} \text { or } / 4 \text { ' }}{\text { total number of raters }}$

كرايترياى زير جهت ارزشهاى كيفى براى CVI استفاده

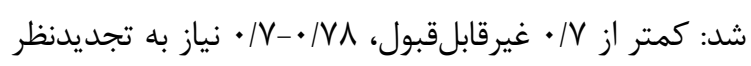

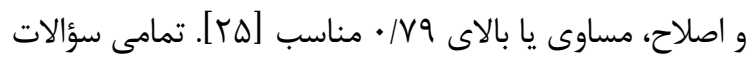

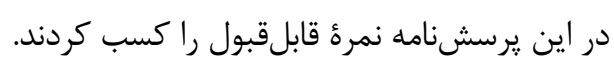

\section{روايى صورى}

در ابتدا روايى صورى با دو روش كمى و كيفى بررسى

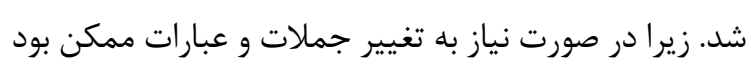
روايى كل ابزار تغيير كند [1/]]. 
بلمنظور تعيين پايايى يرسشنامه در بُعد تكراريذيرى از

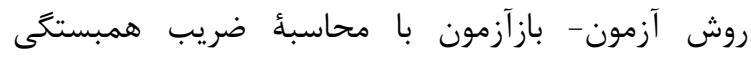

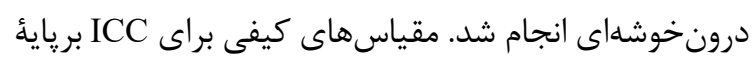

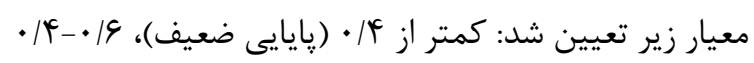

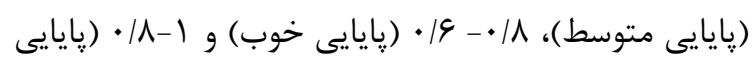
عالى) توصيف مىشود [عr].

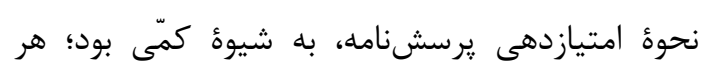

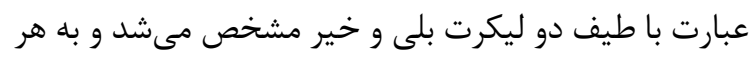

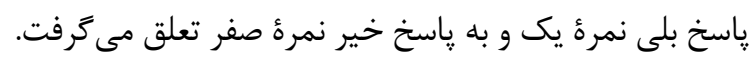

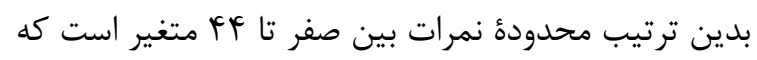
نمرات بيشتر نشاندهندة نياز آموزشى بالاتر و نمرءٔ كمتر نئر

$$
\text { بيانكر نياز آموزشى كمتر است. }
$$

ملاحظات اخلاقى با رعايت وفادارى در ترجمأ متون و و واست

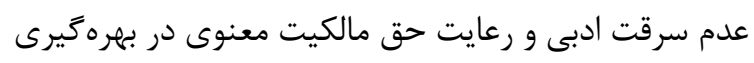

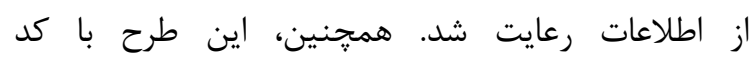

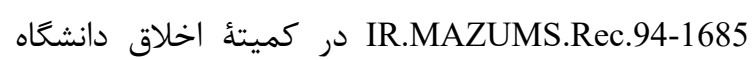
علوميزشكى مازندران ثبت شده است.

بافته ها

نتايج بررسى مطالعات و و جمعآورى نظرات ز زنان هيستركتومىشده و خبركان در فاز اول باعث استخراج هو هبات عبارت

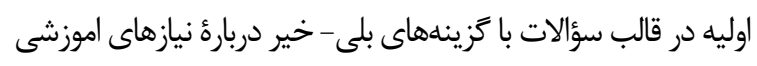

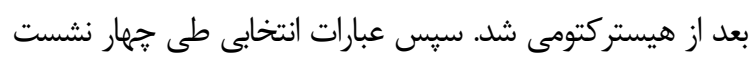
توسط تيم تحقيق بررسى شد و گَويههاى داراى مفاهيم مشترى

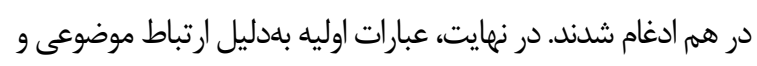

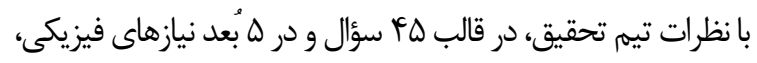
روانى -عاطفى، جنسى، مراقبتى و ساير نيازها طبقابندى شدئ نداند.
از محاسبة نسبت روايى محتوا كه به صورت حاصل كسرى

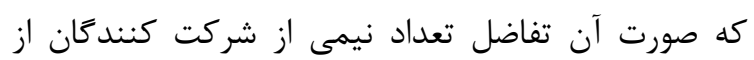

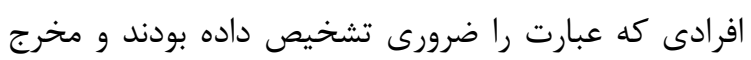

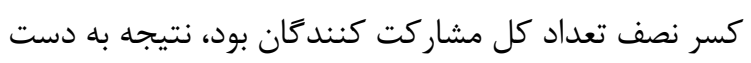

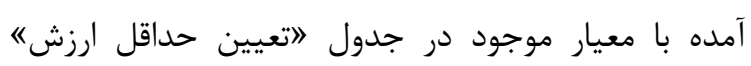

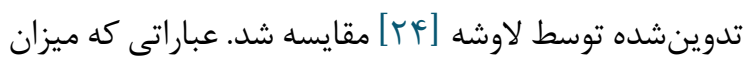

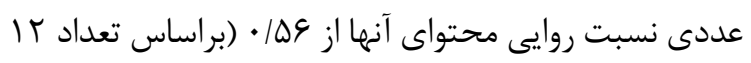

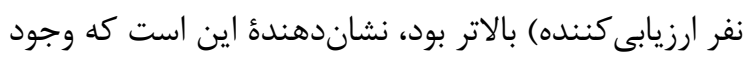

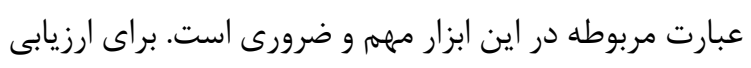

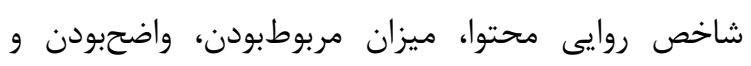

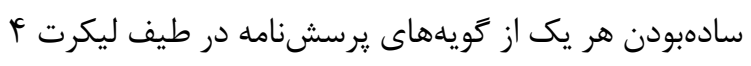
درجه اى توسط همين گروه از متخصصان، تعيين شد. امتياز

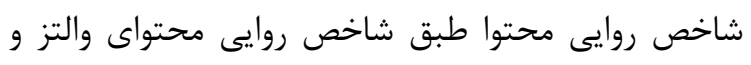

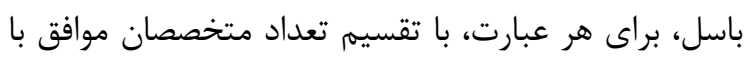

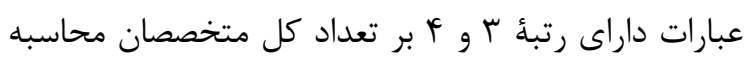

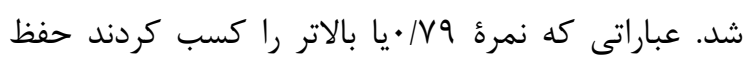
شدند [ro].

\section{بايايى}

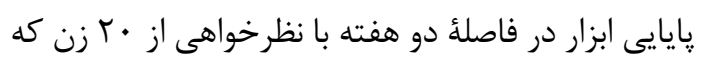

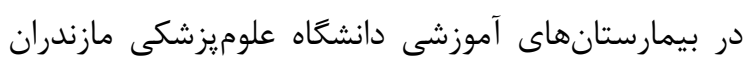
هيستر كتومى شدند، بررسى شد.

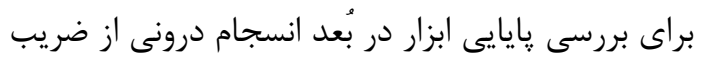

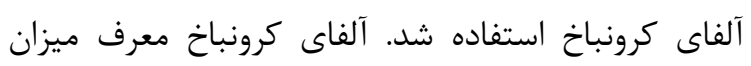

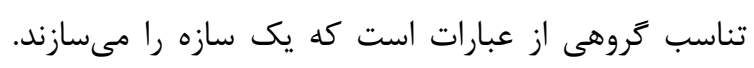

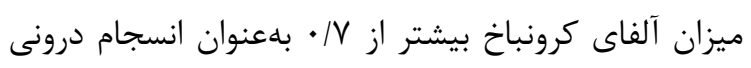

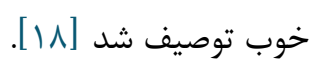

جدول ا. سؤالات نسخهُ اوليهُ يرسشنامه و حذف، قبول يا بازنترى

\section{حذف، قبول يا بازنكرى}

\section{سؤالات}

\begin{tabular}{|c|c|}
\hline \\
\hline \multicolumn{2}{|l|}{ قبول قبول } \\
\hline قبول & \\
\hline بازنحرى & \\
\hline قبول & \\
\hline قبول & \\
\hline قبول & \\
\hline & \\
\hline
\end{tabular}

كوفتكى / درد

شلى شكم/آويزانشن شند

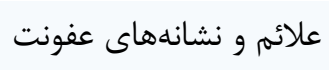

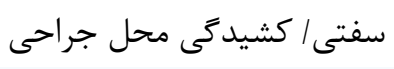
تراشيدن موى محل جراحى محلى جرئ

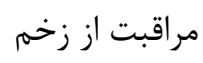

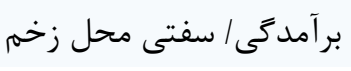

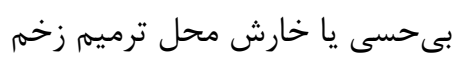


• إ طراحى و روانسنجى نسخة فارسى يرسشنامة نيازهاى آموزشى زنان بعد از هيستر كتومى.

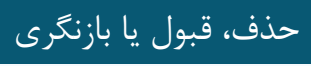

سؤالات

قبول

قبول

بازنخرى

قبول

قبول

قبول

قبول

قبول

قبول

قبول

قبول

قبول

بازنگرى

قبول

قبول

بازنگرى

قبول

قبول

قبول

بازنخرى

حذف

قبول

قبول

قبول

قبول

قبول

قبول

قبول

قبول

بازنگرى

قبول

قبول

قبول
محدوديت فعاليتى

مشكل خواب در شب

تعيين ميزان مناسب فعاليت فيزيكى و ورزش بعد از درب جراحى تجويز داروى ملين

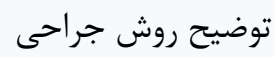

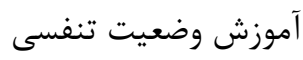

مدت اقامت در بيمارستان

تغيير در فعاليت روده و سيستم گوارشى دئ دئمان

زخم/ خشكى كلو ناشى از بيهوشى رودي

تهوع و استفراغ زحماغنى

داروهاى گوارشى نموع

عملكرد عمومى مثانه

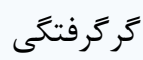

هورمون درمانى بعد از خروج تخمدان

لكهبينى و خونريزى

ترشحات عادى و نرمال وازثن

كاهش اشتها

رثيم غذايى مناسب

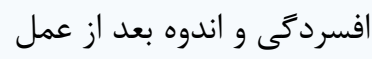

احساس ناخوشايند ناشى از خروج اركان زنانه

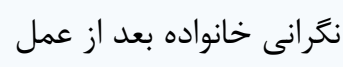

نكرانى از افزايش وزن نكراني

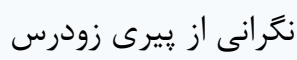

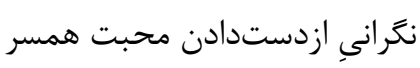

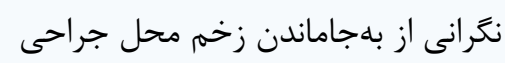

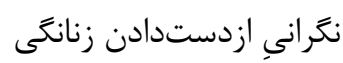

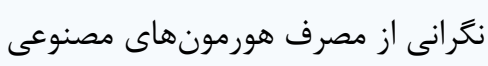

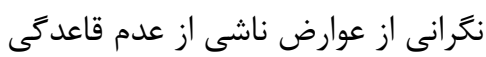

خشكى وازرن

مقاربت دردناك

احساس يا لذت جنسى بعد از هيستر كتومى دردئ

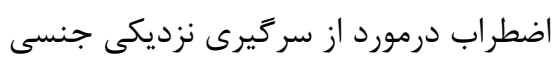

زمان شروع نزديكى جنسى دردي 


\section{حذف، قبول يا بازنگرى}

قبول

قبول

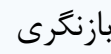

قبول

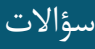

ارائُٔ اطلاعات مناسب سلامت جنسى به همسر در ارتباط

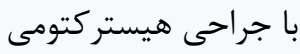

زمان ويزيت و معاينه بعد از عمل توسط يزشك هي

معاينات روتين مامايى / پاباسمير و معاينهُ يُستان

صورتحساب بيمارستان (يوشش بيمه/ هزينه)
نشان داد همأ عبارات بهجز يك عبارت، از نسبت روايى مناسب

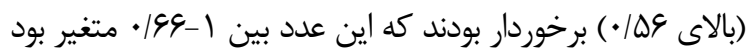

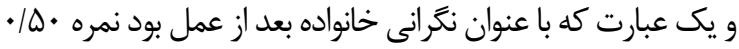
را كسب كرد و حذف شد. بررسى CVI و CVR اين يزوهش نيز

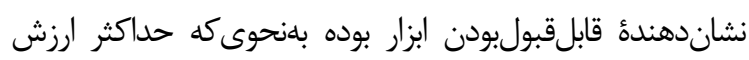

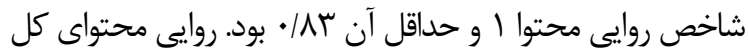

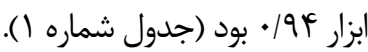
هايايى ابزار فوق با بررسى ضريب آلفاى كرونباخ براى كل ابزار

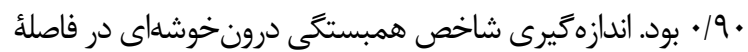
زمانى دو هفته نشان داد كه اين ابزار از ثبات برخوردار است درات

(جدول شماره T) (ICC=•/9V)
در مرحلة بررسى روايى صورى كيفى ابزار و باتوجلبه نظرات مشاركت كنندكان، عبارات اوليه ازنظر سطح دشوارى، ميزان تناسب كران و وجود ابهام بازبينى شدند. نتايج روايى صورى كمى يرسشنامئ نيازهاى آموزشى زنان هيستركتومىشده نشان داد كه نمرئ

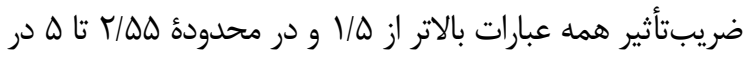
تغيير است. در مرحلة بررسى روايى محتوايى كيفى ابزار باتوجلبه

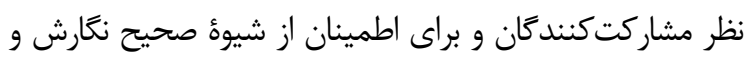

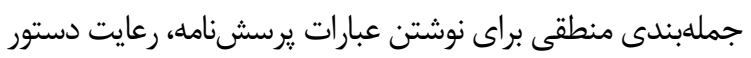

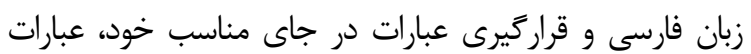
توسط تيم تحقيق جندين بار بازخوانى شد و ورات نظرات

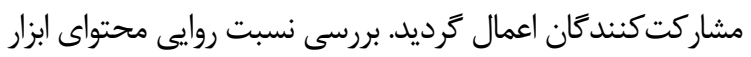

جدول r. شاخصهاى روايى صورى و محتوايى يرسشنامهُ نيازهاى آموزشى زنان هيستركتومىشده

\begin{tabular}{|c|c|c|}
\hline شاخص روايى محتوا & نسبت روايى محتوا & 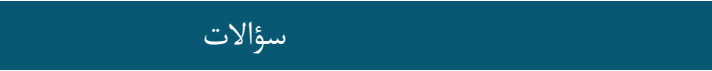 \\
\hline 1 & 1 & كوفتتى / درد \\
\hline 1 & $\cdot 199$ & شلى شكم/آويزان شدن \\
\hline 1 & 1 & علائم و نشانهاى عفونت \\
\hline 1 & $\cdot / \Lambda r$ & سفتى و يا كشيدگى محل ترميم زخم جراحى \\
\hline$\cdot / 91$ & - & تراشيدن موى محل جراحى \\
\hline 1 & 1 & مراقبت از زخم م م \\
\hline 1 & $\cdot 199$ & برآمدگى/ سفتى محل زخم \\
\hline 1 & - & بى حسى يا خارش محل ترميم زخم جراحى \\
\hline 1 & 1 & 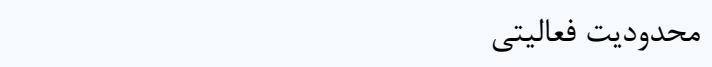 \\
\hline 1 & 1 & 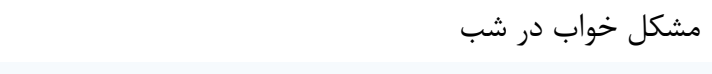 \\
\hline 1 & 1 & تعيين ميزان مناسب فعاليت فيزيكى و ورزش بعد از جراحى \\
\hline 1 & 1 & 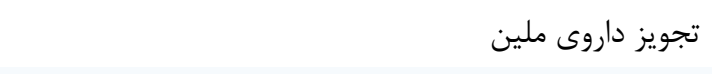 \\
\hline 1 & •/Ar & 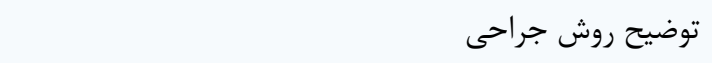 \\
\hline .191 & .199 & آموزش وضعيت تنفسى \\
\hline
\end{tabular}


TIT طراحى و روانسنجى نسخءٔ فارسى برسشنامةٔ نيازهاى آموزشى زنان بعد از هيستركتومى

\section{نسبت روايى محتوا شاخص روايى محتوا}

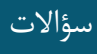

\begin{tabular}{|c|c|c|}
\hline 1 & 1 & مدت اقامت در بيمارستان \\
\hline 1 & 1 & تغيير در فعاليت روده و سيستم گوارشى \\
\hline 1 & $\cdot \operatorname{l\Lambda ~}$ & زخم/ خشكى كلو ناشى از بيهوشى \\
\hline 1 & 1 & تهوع و استفراغ \\
\hline . $/$ A & .199 & داروهاى توارشى \\
\hline 1 & 1 & عملكرد عمومى مثانه ع \\
\hline 1 & 1 & احساس كَرَرفتتى بعد از عمل \\
\hline .191 & $\cdot / \Lambda r$ & هورمون درمانى بعد از خروج تخمدان \\
\hline 1 & 1 & 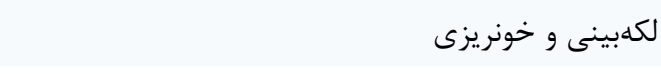 \\
\hline 1 & 1 & ترشحات عادى و طبيعى وازن بعد از عمل \\
\hline 1 & 1 & 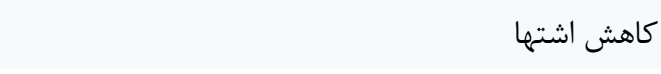 \\
\hline 1 & 1 & رزيم غذايى مناسب \\
\hline 1 & 1 & 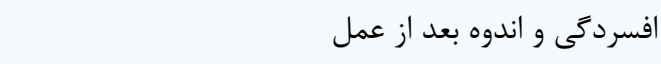 \\
\hline 1 & 1 & احساس ناخوشايند ناشى از ازدستدادن اندام زنانه \\
\hline 1 & $\cdot / \Lambda \mu$ & نكرانى از افزايش وزن ل \\
\hline 1 & 1 & 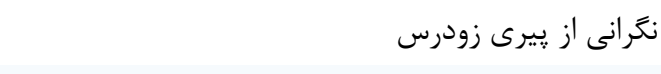 \\
\hline .191 & 1 & نكراني ازدست دادن محبت همسر \\
\hline .191 & .199 & نكرانى از بهجاماندن زخم محل جراحى \\
\hline$\cdot / \wedge r$ & $\cdot / \Lambda$ & 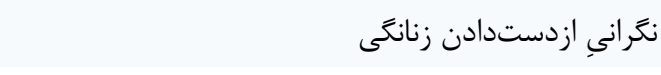 \\
\hline 1 & $\cdot / \Lambda \mu$ & نكرانى از مصرف هورمونهاى مصنوعى \\
\hline 1 & 1 & نكرانى از عوارض ناشى از عدم قاعدگى \\
\hline .191 & 1 & خشكى وازن \\
\hline 1 & 1 & 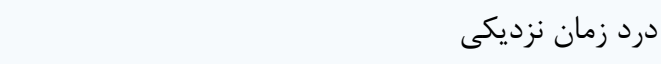 \\
\hline$\cdot / \Lambda r$ & 1 & احساس يا لذت جنسى بعد از هيستركتومى \\
\hline 1 & 1 & اضطراب درمورد از سركيرى نزديكى جنسى \\
\hline 1 & 1 & زمان شروع نزديكى جنسى \\
\hline \multirow[t]{2}{*}{1} & 1 & ارائٔ اطلاعات مناسب سلامت جنسى به همسر در ارتباط \\
\hline & & با جراحى هيستركتومى \\
\hline 1 & 1 & زمان ويزيت و معاينه بعد از عمل توسط يزشك \\
\hline 1 & 1 & معاينات مامايى/ پاٍاسمير و معاينهُ پِستان \\
\hline 1 & .199 & صورتحساب بيمارستان (يوشش بيمه/ هزينه) \\
\hline
\end{tabular}


جدول ب. ضريب آلفاى كرونباخ و همبستخى درونخوشهاى ابعاد يرسشنامئ نيازهاى آموزشى زنان هيستر كتومىشده

\begin{tabular}{|c|c|c|c|c|}
\hline \multicolumn{2}{|c|}{ 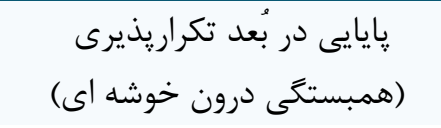 } & \multicolumn{2}{|c|}{ 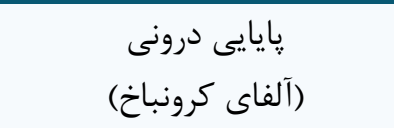 } & \multirow[t]{2}{*}{ ابعاد } \\
\hline & حداكثر & حداقل & ميانخين & \\
\hline 1 & $\cdot|V|$ & .19 & $\cdot / \wedge \Delta$ & فيزيكى \\
\hline 1 & . & .191 & . IAT & روانى - عاطفى \\
\hline 1 & •lA & .198 & .19 & جنسى \\
\hline 1 & $\cdot|\Lambda|$ & .199 & .119 & مراقبتى \\
\hline 1 & $\cdot \mid \Lambda F$ & .191 & .19 & ساير نيازها \\
\hline 1 & .199 &.$/ 98$ & .19 & كل \\
\hline
\end{tabular}

نفر زن هيستر كتومىشده به فاصلة f أ روز و آلفا كرونباخ براى

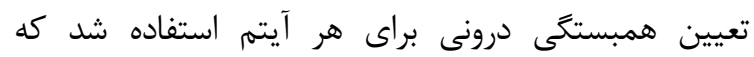

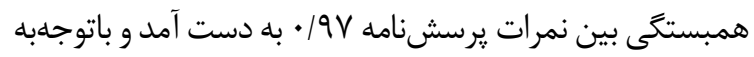

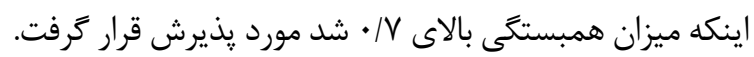

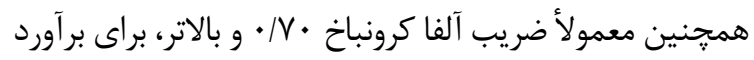
״ايايى قابل قبول است و مقادير پايين تر از آن، پايايى كمتر محسوب مىشود. آلفاى كرونباخ • 9 • محاسبه شد. يافتهها نشان داد كه ابعاد نيازهاى آموزشى زنان لنان

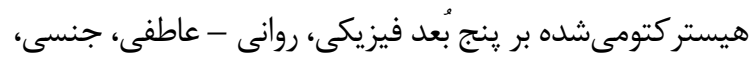

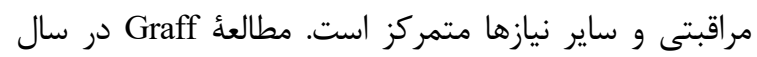

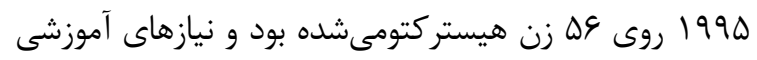
بعد از هيستر كتومى را بررسى كردند؛ ابزار طراحى شدهُ مطالعئ آنها كيفى در قالب هم سؤال و أl حيطئ اصلى شامل انسزيون جراحى، فعايت فيزيكى، متفرقه، وضعيت گوارشى، وضعيت

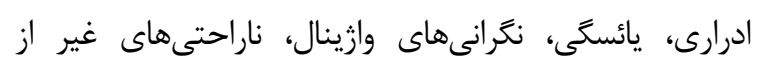

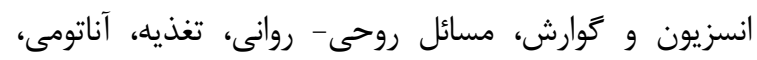
تمايلات جنسى و حفظ سلامتى بود [19]. ولى در مطالعُ

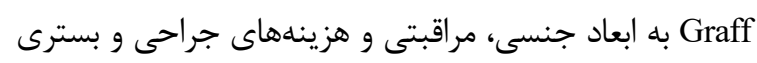

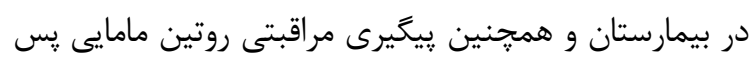

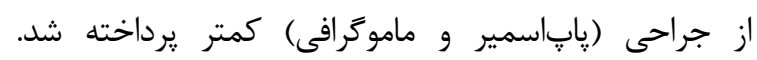

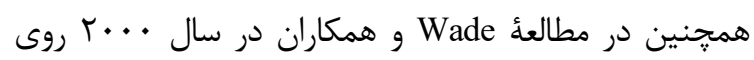

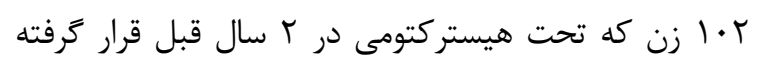

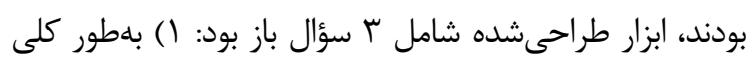

جار جوب مطالعأه حاضر در قالب مطالعهاى روش شناختى بر

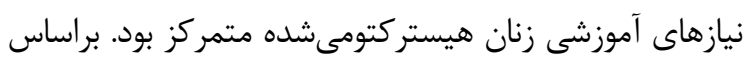
جستجوى محققين در منابع دردسترس به همراه نظرخواهى از

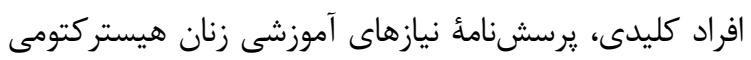

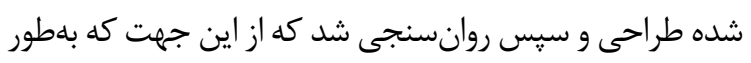
جامع به نيازهاى آموزشى زنان هيستركتومى شده در در ابعاد مختلف توجه كرده است، مى تواند نقطهقوتى براى مطالعهُ حاضر

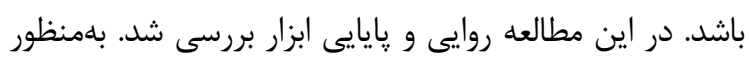
بررسى روايى، از روايى صورى و محتوا استفاده شد. اعتبار

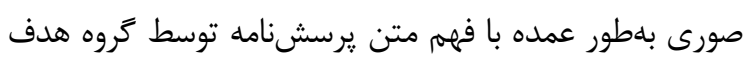

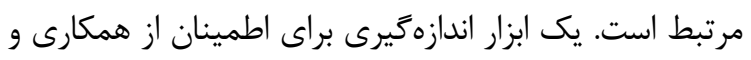

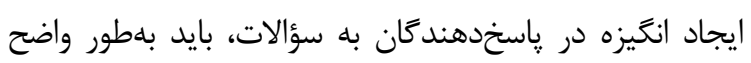
توسط گروه هدف درك شود. زنان هيستر كتومى شده، نظرات خود را درمورد تناسب، انسجام سؤالات و درك از مفاهيم بيان

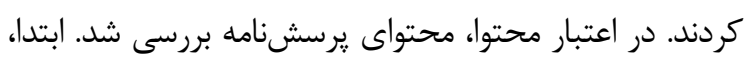

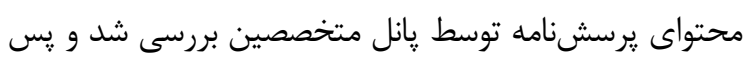

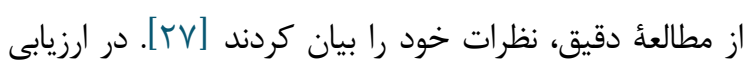

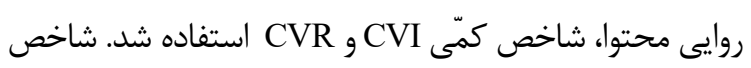
CVR براى همؤ آيتمها بهجز يك آيتم بالاتر از معيار جدول مدول

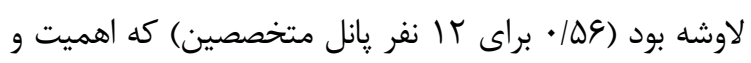

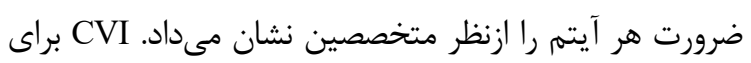
هر آيتم، بالاتر از V9/ • بود و بنابراين مناسب در نظر كر مرفته شد.

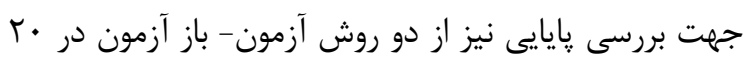


همجنين، از ساير اهداف كاربردى اين مطالعه اين است كه

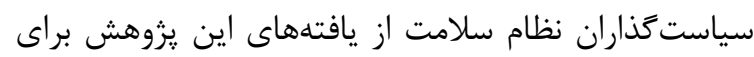

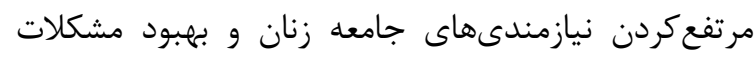

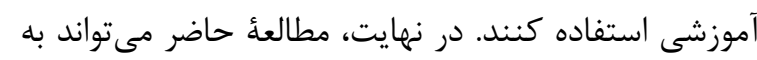

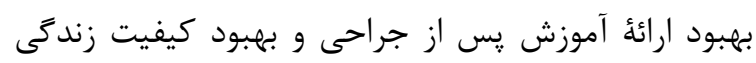
زنان هيستر كتومىشده كمك كند.

$$
\text { سياسگزارى }
$$

اين مقاله بخشى از ياياننامٔ دانشجويى كارشناسىارشد مشاوره در مامايى و حاصل طرح :يزوهشى مصوب دانشگاه

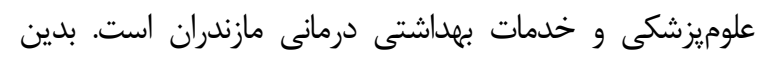

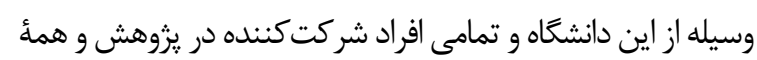
كسانى كه در انجام اين مهم همكارى نمودند، تشكر مى كنيم.

$$
\text { تعارض در منافع }
$$

بين نويسند

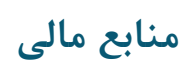

منابع مالى اين مطالعه توسط نويسندكان تامين شده است.

\section{References}

1. Alipour Pour A. Effect of cognitive behavioral therapy in hastening recovery of women after hysterectomy surgery. J Behav Sci. 2010; 4(2):915.

2. Stang A, Kluttig A, Moebus S, Völzke H, Berger $\mathrm{K}$, Greiser KH, et al. Educational level, prevalence of hysterectomy, and age at amenorrhoea: a crosssectional analysis of 9536 women from six population-based cohort studies in Germany. BMC Women's Health. 2014; 14(1):1 -9. [DOI:10.1186/1472-6874-14-10] [PMID] [PMCID]

3. Wade J, Pletsch PK, Morgan SW, Menting SA. Hysterectomy: what do women need and want to know? J Obst, Gynecol, Neonat Nurs. 2000; 29(1):33-42. 6909.2000.tb02754.x] [PMID]

4. Stewart EA, Shuster LT, Rocca WA. Reassessing hysterectomy. Minnesota Med. 2012; 95(3):36-9.

5. Gibson CJ, Thurston RC, El Khoudary SR, SuttonTyrrell K, Matthews KA. Body mass index following natural menopause and hysterectomy with and without bilateral oophorectomy. Int $\mathbf{J}$ Obes. 2012; 37(6):809-13. [DOI:10.1038/ijo.2012.164] [PMID] [PMCID]
تجربئ هيستركتومى خود را جطور توصيف مى كنيد؟ ؟) جه

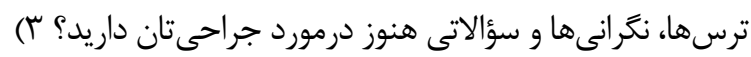

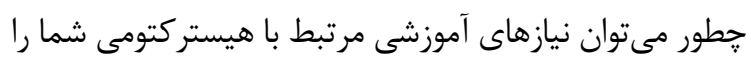

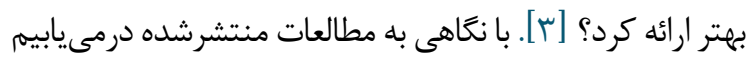

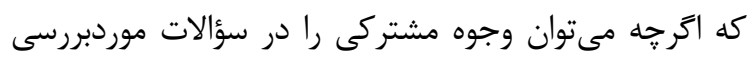

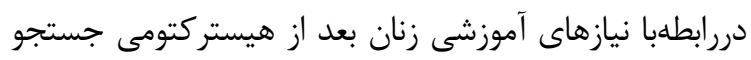

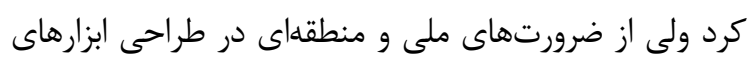
بومى نمىتوان غافل شد.

$$
\text { نتيجه كيرى }
$$

باتوجه به اينكه وضعيت زنان بعد از هيستركتومى

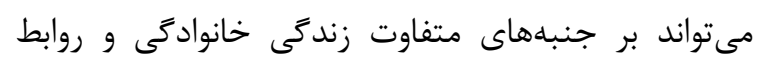
زوجى تأثير بحذارد، اين موضوع مىتواند با تأثيرات منفى منى منى

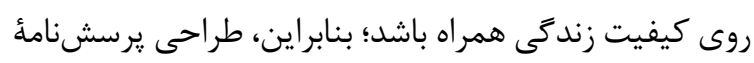

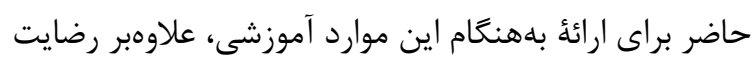

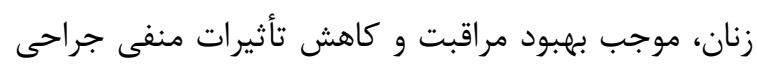

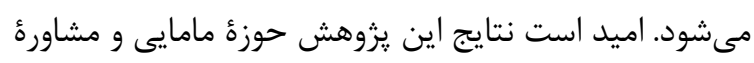

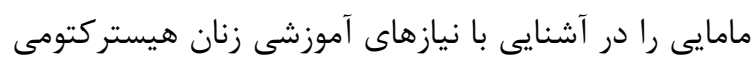
شده بيشازييش كستردهتر كنند و اين نتيجه در ادامه منتج به مراقبت بهتر و افزايش و بهبود كيفيت مراقبت شود.

6. Cohen S, Hollingsworth A, Rubin M, Graff B, Thomas J, Wehry L. Psychosocial adaptation during recovery from hysterectomy. Webmed Cent Obst Gynaecol. 2011; 2(3):1-8.

7. Maryami Z, Modarres M, Taavoni S, Foroushani AR. Effect of Foot Massage on Pre- and Post Hysterectomy Anxiety. Hayat: J School Nurs Midwifery. 2013; 19(1):65-75.

8. Badakhsh MH, Taftachi F, Mehrabi F, Derakhshan A. The Effect of Hysterectomy in Securing Sexual Desire and Satisfaction. Iran J Surg. 2009; 17(1):75-80.

9. Wang $\mathrm{F}, \mathrm{Li} \mathrm{CB}, \mathrm{Li} \mathrm{S}, \mathrm{Li}$ Q. Integrated interventions for improving negative emotions and stress reactions of young women receiving total hysterectomy. Int J Clin Exp Med. 2014; 7(1):3316.

10. Tutuncu B, Yildiz H. The Influence on Women's Sexual Functions of Education Given According to the PLISSIT Model after Hysterectomy. ProcediaSoc Behav Sci. 2012; 47(2012):2000-4. [DOI:10.1016/j.sbspro.2012.06.939] 
11. Akani NA, Akani CI, Pepple DK. Hysterectomy in Adolescents, in Port Harcourt, Nigeria. Nigeria Health J. 2013; 8(1-2):20-3.

12. Nosrait M, Rahmani AR, Naghibi FS, Razavi A. A Study on The Effects of Education on Marital Life Satisfaction of Women Undergone Hysterectomy in Urmia Chosen Hospitals,1386. J Nurs Midwifery Urmia Uni Med Sci. 2007; 5(3):128-33.

13. Nilchian F, Skini M, Jabbarifar SE. Identification of educational needs to promote oral health from the standpoint of patients referring to Shariati dental clinic in Isfahan: a qualitative research. J Isfahan Dent School. 2012; 7(5):790-7.

14. Neefus MS, Taylor ME. Educational needs of hysterectomy patients. Patient Couns Health Edu. 1982; 3(4):150-5. [DOI:10.1016/S07383991(82)80006-2]

15. Dehghani A, Mohammadkhan-Kermanshahi S, Memarian R. Evaluation of the Needs of Patients with Multiple Sclerosis. Zahedan J Res Med Sci. 2012; 14(9):104 -6.

16. Graff BM. Expression of learning needs and teaching provided during post-abdominal hysterectomy convalescence (PhD Dissertation). Pennsylvania: University of Pennsylvania. 1995?.

17. Sahebozzamani M, Rashvand F. The study of training demands of MS patients, members of Iran's MS Society in 2007. Med Sci J. 2008; 18(3):195-9.

18. Azam Salehi, Marjan Ahmad Shirvani, Noraddin Mousavi Nasab, Shahhosseini Z. Development and Psychometry of An Instrument to Measure the Educational Needs of Health Care Providers in Prenatal Screening. J Mazandaran Univ Med Sci. 2018; 27(156):117-28.

19. Wukasch RN. The post-hysterectomy experience of women: a cross-sectional study. Indiana Uni; 1993.

20. Musil CM. Self-coherence, coping, and mood in women following hysterectomy. Case West Reserve Uni; 1991.

21. Oetker-Black SL, Jones S, Estok P, Ryan M, Gale N, Parker C. Preoperative teaching and hysterectomy outcomes. AORN J. 2003; 77(6):1215-31. 2092(06)60983-6]

22. Shirazi M, Manoochehri H, Zagheri Tafreshi M, Zayeri F. Development and psychometric evaluation of chronic pain acceptance instrument in the elderly. Anesth Pain. 2015; 5(2):33-47.

23. Lasch KE, Marquis P, Vigneux M, Abetz L, Arnould B, M B. PRO development: rigorous qualitative research as the crucial foundation. Qual Life Res. 2010; 19(8):1087-96. [DOI:10.1007/s11136-010-9677-6] [PMID] [PMCID]

24. Shahhosseini Z, Simbar M, Ramezankhani A, Alavi Majd H. Designing and psychometric properties of a questionnaire for assessing female adolescents' health needs. J School Pub Health Inst Publ Health Res. 2011; 9(1):11-22.

25. Ghasemi E, Janani L, Dehghan Nayeri N, Negarandeh R. Psychometric Properties of Persian Version of the Competency Inventory for Registered Nurse (CIRN). Iran J Nurs. 2014; 27(87):1-13. [DOI:10.29252/ijn.27.87.1]

26. Corson M A, Boyd T, Kind P, Allen P. Measuring oral health: does your treatment really make a difference. $\mathrm{Br}$ Dent J. 1999; 187:481-4. [DOI:10.1038/sj.bdj.4800310] [PMID]

27. Hosseinkhani Z, Nedjat S, Majdzadeh R, Mahram M, Aflatooni A. Design of the child abuse Questionnaire in Iran. J School Pub Health Inst Public Health Res. 2014; 11(3):29-38. 